\title{
LA MADRE SOLTERA FRENTE A LA SOCIEDAD
}

\author{
M. Isabel Arbiza Berregui
}

La moral colectiva de los pueblos o grupos sociales, a medida que éstos avanzan en la comprensión científica y racional de los fenómenos diversos, es decir, en su culturización, pierde su rigidez intolerante e irracional y se enriquece abarcando actitudes, ideologías, comportamientos, etcétera, que difieren de la norma imperante, sin ser por ello menos valiosos ni respetables.

Pero, mientras en algunos campos, esta moral social evoluciona al compás del tiempo, en otros (especialmente en los relacionados con la sexualidad y concretamente con la femenina), conserva restos arcaicos que crean desfases y desniveles en lo que había de ser un desarrollo armonioso de la mentalidad colectiva y del pensar y proceder de sus componentes.

Dentro de las lagunas o marginaciones ejercidas sobre grupos determinados, hemos estudiado el caso específico de las madres solteras y del montaje mental y real que existe: en su contra.

Hemos actuado a dos niveles: Uno personal, entrevistando a madres solteras, individualmente. Otro, social, visitando los Centros de Asistencia creados para ellas. Entre ambos, hemos seguido los pasos de una madre soltera, desde su embarazo hasta su lucha diaria por integrarse con su hijo en la sociedad. También hemos incidido en el aspecto judicial.

Hubiéramos querido completarlo con un sondeo en empresas (a nivel de colocación), colegios (en cuanto a dificultades para ingresar al niño), y finalmente un sondeo callejero (mercados, bares, espectáculos). No fue posible por falta de tiempo, pero los resultados obtenidos hablan por sí solos y creemos que reflejan la opinión general y la situación actual con bastante fidelidad. 


\section{Introducción}

La normativa moral socialmente imperante, protegida por la sombra machista de dominancia patriarcal, establece códigos de comportamiento sexual diferentes para los sexos masculino y femenino y, si hay transgresión de una norma, la sanción, tanto jurídica como social, es mucho más fuerte para la mujer que para el hombre; en casos como el que nos ocupa, se considera una falta de tal calibre que ha de pagarse durante toda la vida.

La discriminación que la mujer sufre con respecto al hombre a todos los niveles se agudiza en el caso de las madres solteras que, desde el momento en el que la sociedad les cuelga la etiqueta de marginadas, por el simple hecho de haber tenido un hijo fuera del cauce establecido, se enfrentan con un futuro desolador plagado de marginaciones y restricciones, tendentes a impedir un auténtico desarrollo en todas las facetas de la vida personal y de relación humana, tanto de la madre como del hijo.

La Conferencia Internacional sobre los Derechos Humanos, reafirmando la Declaración sobre la eliminación de la discriminación contra la mujer, que ya había sido adoptado en 1967 por la ONU, especifica en su artículo 3.०: «Deberán tomarse todas las medidas apropiadas para educar a la opinión pública y dirigir las aspiraciones nacionales hacia el desarraigo de los prejuicios y la abolición de: las costumbres y de cualquier otra práctica basadas en la idea de la inferioridad de la mujer.»

No obstante, ningún poder público se ha molestado en impedir que, hoy todavía, tener un hijo sea para algunas mujeres un drama aterrador, que les supone cambiar bruscamente de vida, romper con todo lo anterior y quedar para siempre marcadas, distanciadas, rebajados todos sus derechos, solas ante la responsabilidad, angustiadas por la presencia de un hijo a quien alimentar, cuidar, querer, proteger, contestar...

A fin de conocer más de cerca este problema, hemos realizado una serie de visitas a Centros Asistenciales y Organizaciones relacionadas con esta cuestión; por otra parte, hemos entrevistado a madres solteras para 
ver qué hace la sociedad, por un lado, y qué opinan las interesadas, por otro.

Aunque hemos procurado incidir en los más importantes, no todos los aspectos que afectan a la madre soltera han podido ser investigados con la debida precisión. No obstante, creemos que los resultados aportan datos suficientes para comprender que estamos ante un caso de mentalización social que nos afecta a todos.

\section{Embarazo}

El drama se inicia ante la certeza del embarazo. La primera y principal dificultad de la mujer soltera embarazada está en el rechazo y acusación que sufre por parte de su familia, que la considera culpable de un delito y que se desentiende de su situación económica y personal y de la de su futuro hijo.

Curiosamente, las familias económicamente menos favorecidas apoyan más a la futura madre soltera, al contrario de las familias de nivel económico más elevado, en las que se antepone el honor familiar y el prestigio social. Es antes la norma que la persona. Una mujer con un hijo y sin marido no está bien vista. Así, en el momento en el que más ayuda necesita, la familia la abandona a su suerte, sin querer saber nada del «escándalo». El hijo, que con un marido al lado se convertiría en una gran alegría, pasa a ser una gran desdicha.

La otra postura fundamental a considerar es la del padre del niño, que la mayor parte de las veces se evade por completo de su responsabilidad. En su mayoría se trata de hombres ya casados, y novios en menor proporción. Un porcentaje elevadísimo proponen el aborto como única solución y si no es aceptado se desentienden del asunto; otros desaparecen; otros, los menos, aceptan al hijo.

Aquí es donde comienza a surgir la injusticia en todo su esplendor. $\mathrm{El}$ señor que además de su legítima esposa tiene una amiga o sale a veces con otra mujer, decide ignorar las consecuencias de sus actos y se sumerge impunemente en su inmunidad de persona respetable. Se ha dado el caso de un médico, ginecólogo, que dejó embarazada a su sirvienta y la puso en la calle al tener noticia de la situación. Luego está el novio, que parecía tan simpático y que decide tomarse unas vacaciones un poco largas... Y mientras tanto, la que no puede escurrir el bulto se queda con la consternación de saberse abandonada y la angustia de sentir crecer su vientre a la par que su vergüenza, su miedo... Miedo a que se enteren los amigos, las vecinas, en el trabajo. No es la primera a la que han despedido o «ha tenido que irse». 
Trabajaba de profesora en un colegio de religiosas, del que, al enterarse de mi estado, me despidieron. ${ }^{1}$

Conferencia Internacional sobre los Derechos Humanos (1968): «Para impedir la discriminación contra las mujeres basada en el matrimonio o maternidad, y asegurar su derecho efectivo al trabajo, deben tomarse medidas a fin de impedir el despido en caso de matrimonio o maternidad y de proveerlas de permiso con sueldo por maternidad, asegurarles la vuelta al empleo que tenían anteriormente y proporcionarles los servicios sociales necesarios, incluyendo los servicios de guardería.»

El temor y la desesperación lleva a la mayoría a tratar de abortar en manos de cualquiera.

Cuando me quedé en estado fue un tormento. Estaba sola en Barcelona y no sabía qué tenía que hacer. Busqué a una persona que, según me dijeron, no fallaba nunca $y$, por tanto, sin riesgos ni peligros. Me cobró 25.000 ptas. y casi me mata. Me asusté mucho y no quise que continuara.

Estoy totalmente a favor del aborto, como derecho de toda mujer, pues concebir un hijo sin desearlo no se lo aconsejo a nadie, al margen de que después se acepte, pues en la realidad este hecho puede partir a una persona totalmente en la mayoría de sus planes. Yo volví a quedar embarazada, por fallo propio, pues utilizaba anticonceptivos. En esta segunda ocasión aborté, pues no quería volver a pasar lo de antes. Y ése fue uno de los peores momentos de mi vida; nunca he vuelto a ser ni a estar como antes. Incluso a nivel fisiológico empecé a tener desórdenes.

El aborto no es una cuestión de valor o cobardía. Si una mujer no quiere sufrir ni afrontar las vicisitudes que se le puedan presentar, pues adelante. No es mejor ni peor. Nadie tiene derecho a criticar. Es la mujer y su problema. Eso sí, se deben dar facilidades y seguridad para que no tengamos que ponernos en manos de carniceras sin escrúpulos que se aprovechan de nuestra desgracia.

No todo el mundo tiene dinero, ni oportunidad, ni conocimiento, ni medios, para abortar en el extranjero.

1. Todos los párrafos entrados son opiniones o declaraciones de las madres solteras entrevistadas. 
El aspecto preventivo no es más sencillo. En la Maternidad, el sterilete no lo ponen si no es con el consentimiento del marido. La mujer que decide usar este método por sí misma no puede, tiene que llevar al marido, pues «siempre hay desaprensivos que ponen querellas al médico, si éste lo coloca mal y hay desprendimientos y derrames. La ley para prevenir estos casos obliga a que el marido dé su conformidad».

La gran mayoría de mujeres solteras embarazadas provienen de clases trabajadoras, de burguesía media; obreras, empleadas, maestras, mujeres confradas e ignorantes. Ignorancia feroz, siempre fuente de sumisión, de temor y que en este caso a causa de una nula información sobre anticonceptivos y medidas preventivas provoca el que casi todos los embarazos sean por accidente y muchas veces tras engaño del padre del niño, que además no se preocupa en absoluto del riesgo de embarazo. Tan lamentable como la falta de escrúpulos es la falta de información en este sentido; lamentable e incomprensible.

Los anticonceptivos vendrían a limar este problema. No entiendo por qué no se pueden vender libremente. Una mujer casada tiene más facilidades para conseguirlos, pues el médico se los receta como medio preventivo de salud. La Seguridad Social tendría que hacer algo al respecto.

No se entiende que una sociedad que condena hasta tal punto el hecho de tener un hijo fuera del matrimonio no ponga, a disposición de todos, los medios precisos para que esto no ocurra. Tropezamos siempre con la arcaica moral, restrictiva para unas, permisiva para otros. Con una mentalidad tacaña, que se aterra de que una mujer haga el amor fuera del sacrosanto matrimonio.

En el momento en que escribimos este artículo ha sido publicado el nuevo decreto-ley que despenaliza el adulterio y de algún modo legaliza los anticonceptivos. Este aspecto legal es muy importante, pero cobrará mayor sentido si viene acompañado de una adecuada campaña de divulgación y mentalización popular, a todos los niveles y edades.

Una buena educación evitaría muchos errores y muy malos ratos y tratos.

\section{Centros Asistenciales}

Entre desesperadas y resignadas, enviadas por médicos, comadronas, asistentas sociales, sacerdotes, etcétera, gran parte de estas mujeres ilegal- 
mente embarazadas acuden a dar a luz a un Centro Asistencial para madres solteras, muchas de ellas (más de un $50 \%$ ) tras fallidos intentos de aborto.

La existencia de estos Centros es uno de los anacronismos incomprensibles que subsisten en nuestra sociedad. No solamente por su clara función discriminadora, sino por el efecto, la mayor parte de las veces negativo, que producen en las mujeres que no tienen más remedio que acudir a ellos.

El tipo de instituciones que en la actualidad se cuidan de acoger a las madres solteras se han de abolir, pues marginan tanto a la madre como al niño, ya que las personas que los dirigen empiezan por tener un planteamiento nefasto considerando que los niños son «hijos del pecado», por lo que no pueden asumir el problema en su verdadera dimensión.

La llamada «Casa de Maternidad» de Barcelona, dependiente de la Diputación Provincial, es un impresionante edificio, rodeado de un alto muro protector de la noción de delito que flota en su interior (las «reincidentes» no son aceptadas), donde las distinciones comienzan en la misma puerta: una entrada para «solteras» (embarazadas solteras) y otra, al lado opuesto del edificio, para «parturientas» (embarazadas casadas).

Un gerente se ocupa de administrar la Institución, con la colaboración de un psicólogo, dos asistentas sociales y 120 puericultores. El excedente de personal se refleja en el hecho de que solamente haya 150 niños (han llegado a tener de 800 a 1.000), lo que explica el interés que ponen en la adopción, tema al que nos referiremos más adelante.

Se ingresa al octavo mes de embarazo, es decir, para dar a luz. Para las que no tienen el apoyo económico de un hombre, la estancia y el parto son gratuitos, aunque tienen opción a pagar el parto, cosa que ninguna ha hecho en los últimos dieciséis años, lo que la asistenta social comenta con desagrado. En palabras del gerente: «Son unas desagradecidas.» Si viven con un hombre, han de pagar 30.000 pesetas de parto por mala que sea su situación económica. Cumplen una jornada laboral de ocho horas, cobrando 19.000 pesetas netas al mes. Hay servicio de guardería, por lo que pueden residir aquí hasta que el niño tenga aproximadamente cuatro años.

Las cuotas y condiciones de admisión varían según las Instituciones. En el Hogar Santa Isabel (Guinardó) se ingresa hacia el quinto mes de embarazo. Regentado por una orden religiosa (Siervas de la Pasión de Cristo) se fundó a primeros de siglo con el fin de ayudar a las madres solteras; cuenta con una subvención del Ministerio de Hacienda, donativos y las cuotas mensuales de las residentes. Hay lugar para 35 de ellas que, 
si trabajan fuera, pagan 2.500 pesetas mensuales; la habitación individual supone un incremento de 1.000 pesetas, aunque generalmente duermen en habitaciones de 5 camas y pagan la estancia trabajando en un taller de confección de fundas de colchón que dirigen las mismas monjas. Poseen otro edificio que sirve de residencia a las mujeres que ya son madres, todas las cuales trabajan, por lo que también hay guardería (abierta a cualquier niño del barrio) que cuesta 4.000 pesetas al mes.

La Residencia Santa Eulalia, situada en Sarriá, es una institución privada que funciona en España hace veinte años, creada a partir de una herencia o patrimonio privado, gracias al cual y a las aportaciones de las residentes se mantiene. Cuenta con los servicios de una asistenta social, tres monjas y tres seglares.

En un principio, las residentas eran internas, no trabajaban y podían quedarse hasta que el niño tuviera cuatro años. Eran tiempos de vergüenza y ocultación que desgraciadamente no están tan lejanos. Hay lugar para 25 residentes, para cuya admisión no hay límites de edad, ni diferenciación en cuanto a clase social de procedencia. Esta aclaración se comprende teniendo en cuenta que el pequeño edificio está situado en la zona residencial más tradicional de Barcelona. La estancia cuesta 5.000 pesetas al mes $y$, puesto que hay guardería, pueden quedarse hasta que el niño cumpla dos años.

Con el nombre de Villa Teresita se conoce la organización de monjas seglares que funciona en España desde hace 37 años, al servicio de las madres solteras principalmente, con residencias en Valencia, Madrid, Pamplona, Granada, Canarias, Cádiz y Barcelona (Vallvidrera). El Centro se mantiene con una subvención no fija del Ministerio de Justicia, donativos y las aportaciones de las residentes.

Las mujeres que acceden a este lugar tienen como único requisito el de ser mayores de edad. Su ingreso es voluntario. La cuota es de 3.000 pesetas al mes, si pueden pagarla. No todas las que ingresan están embarazadas, pues se considera en cierto sentido un centro de reinserción social y de reeducación personal.

La Asociación Católica Internacional de Orientación de la Joven, como su nombre indica, es una organización internacional que presta sus servicios como residencia, bolsa de trabajo y todo tipo de información que precisen las jóvenes o mujeres que pasan por este Centro, entre las cuales se cuenta un número no desdeñable de embarazadas. Cuenta con una subvención de Cáritas y donativos de empresas privadas o farnilias. Trabajan en él cerca de 30 personas, en su mayoría asistentes sociales. Hay 44 plazas.

En una línea de ayuda incondicional, está el SOMS (Servicio de 
Orientación a Madres Solteras). Organización nacida del IRES (Instituto de Reinserción Social), se dedica exclusivamente a la orientación (residencia, trabajo, adopción, etcétera) y ayuda de las madres solteras. Dirigido por asistentas sociales, está financiado por Cáritas y cuenta con la colaboración de un tocólogo, psicólogo, abogado, notario. La organización ayuda y apoya a la madre soltera, dentro de los límites posibles, sin plantear ningún programa reivindicativo ni divulgador o mentalizador. Está convencida de que la solución única y total está en la mentalización de la sociedad, de forma que acepte normalmente el hecho de que una mujer tenga un hijo independientemente de estar casada.

En la mayoría de los Centros Asistenciales el régimen de vida es bastante severo.

No creo que den el trato adecuado. Yo no encontré en absoluto cariño, comprensión ni consuelo. Te atienden lo justo. Tienen derecho a tratarte de mala manera y tú a guardar silencio $y$, si no te interesa, la puerta no está cerrada.

En la Maternidad, por ser el más grande, frío y aséptico, no se tiene mayor preocupación por el estado psíquico de las ingresadas. Han de cumplir su horario de trabajo, fuera del cual pueden salir, siempre que estén de regreso para las once de la noche.

En el Hogar Santa Isabel, la vida en la residencia es de enclaustramiento conventual. Los domingos, las residentes regresan para las 8,30 de la noche, pues, en palabras de la superiora: "Qué hace una embarazada a esas horas por la calle.» No es de extrañar que el equilibrio psíquico de las ingresadas, ya de por sí preocupante, se desestabilice y surjan a menudo estados depresivos o agresivos, habiendo habido incluso un intento de suicidio. Aunque se aceptan «reincidentes», no es fácil que cualquiera de las residentes se decida a volver, pues a la vida austera, silenciosa, regada de rezos y sonrisas de perdón, se une, siempre presente, la constancia de la falta cometida que se ha de pagar, del hijo que será un angelito fruto del pecado en el que la madre volcará todo su afecto y abnegación para expiar su culpa.

En este contexto es normal que por lo menos el $50 \%$ de las residentes se sientan culpables, avaladas por la opinión de la superiora, que las considera culpables en un $50 \%$. A todas. El otro $50 \%$ de culpa no se diluye. Es del hombre. Todo embarazo fuera de la norma matrimonial tiene un $100 \%$ de culpa y condena moral. Puede exceptuarse, tal vez, a las que son un poco subnormales, pobrecitas.

Ocasionalmente las visita un psicólogo, pero el Centro cuenta con la 
colaboración permanente de un sacerdote médico, que en grupo o en privado facilita a las residentes la información que deseen, pues su contacto con el exterior es escaso.

La experiencia es culpabilizante y traumatizante en grado sumo.

Tienen más suerte las que van a parar a la Residencia Santa Eulalia. Las residentes ingresan hacia el cuarto o quinto mes de embarazio, pasada la primera crisis y ya hechas a la idea de que van a tener un hijo, lo que no excluye crisis posteriores.

El ambiente es severo y ordenado, pero además de ser una casa espaciosa y tranquila rodeada de jardín que invita al descanso y a la tranquilidad, se tiene algo más en cuenta el estado psíquico y emocional de las ingresadas. El horario de cierre de la guardería son las ocho de la noche, hora para la que han de regresar todas las residentes. Depende del grupo que haya, pueden surgir dificultades en la convivencia, por los distintos niveles sociales y culturales y por la agresividad que se desencadena al haber fallado todo el soporte emocional: hombre, familia, amigos, etcétera, y que el ambiente «gestante» y severo favorece. Algunas residentes se encierran en sí mismas y no tienen interés en colaborar en nada. Se expulsó a una por alterar el orden y no respetar las normas. Hubo otra que se marchó. Se organizan actos colectivos en muy pocas ocasiones y de temas generales que puedan interesar a todas, lo cual no siempre es fácil. Más que nada, se hacen reuniones por cuestiones de convivencia y de la casa. Hay orden, seriedad, limpieza y pocas tonterías. Dentro de esta línea de severidad no se admiten «reincidentes». Un desliz es comprensible, tener más supone una gran falta de seriedad.

Consultar los problemas con un psicólogo o con un psiquiatra les da algo de miedo. Con un cura se desahogan mejor. De cualquier forma no lo piden mucho.

Villa Teresita es, a nuestro juicio, la más humana de las residencias visitadas. Hay un punto fundamental y es que la casa está totalmente al servicio y en función de sus moradoras. Por otra parte, reciben también a otras mujeres socialmente marginadas, especialmente prostitutas, que desean reconsiderar su vida, pues como hemos indicado se trata, hasta cierto punto, de un centro de reinserción social y de reeducación personal.

Hay un mínimo de normas generales y no se establece ningún tipo de vigilancia, tratando de amoldar el ritmo de vida al grupo específico de residentes. La casa la limpian las monjas y la comida la hace una empleada. pues consideran que es más importante estar a disposición de las residentes el mayor tiempo posible. Algunas de ellas estudian o trabajan fuera, mientras su embarazo se lo permite, y otras trabajan en un pequeño taller de plásticos en la misma residencia. Por la noche, los dias laborables han 
de regresar para las diez y los festivos hacia las once y media. Se insiste en la importancia de la libertad de las residentes: «Preferimos estrellarnos dando libertad que coaccionarlas.» La actitud, comprensiva y de ayuda, está impregnada de religiosidad.

No suelen ir mucho al psicólogo y, de cualquier modo, prefieren entrevistarse con un cura, tal vez porque creen que les va a guardar mejor el secreto. En la Institución no les aconsejan directamente ir a uno o a otro, depende de cómo planteen el problema.

En la misma línea, pero de forma más amplia, más dinámica, está la Asociación Católica Internacional de Orientación de la Joven. Por ser un centro internacional, de paso, es frecuentado por mujeres de características diversas en cuanto a nacionalidad, clase social, edad, mentalidad, etcétera. A pesar de ello, la convivencia es buena, favorecida al máximo por las responsables que evitan los proselitismos de cualquier matiz (religioso, político, moral) y tratan de atender cualquier problema que afecte a las residentes, siempre dentro de su línea de ayuda y orientación. Con estas premisas, las jóvenes embarazadas que llegan buscando alojamiento son inmediatamente atendidas.

Generalmente proceden de provincias, son más bien jóvenes, aunque también hay algunas mayores; pero, en general, con una característica común de inmadurez, con un gran desequilibrio afectivo, producto normalmente de conflictos familiares, que les hace estar sensibilizadas al máximo, reaccionando fuertemente frente a cualquier intento de ayuda o acercamiento.

Puesto que llegan a este lugar como último recurso y de manera un tanto precipitada, en primer lugar se intenta tranquilizarlas y calmarlas. Se las coloca en habitaciones individuales y aunque se ha de pagar el alojamiento, no es problema si no tienen dinero. El interés se centra en la persona y su problema (sin juzgarla) y el Centro trata de ser un puente entre la solución a este problema y la calle. Si la joven no tiene ningún recurso, tramitan su ingreso en alguna de las residencias citadas, generalmente la de Santa Eulalia.

Se dan charlas de orientación en cuanto a situaciones de la pareja y problemas psicológicos que se plantean, siempre teniendo en cuenta la carencia afectiva que padecen las interesadas.

Cuentan con la colaboración cie un ginecólogo, en caso de emergencia. También se alojan aquí jóvenes procedentes de la Maternidad, que, tras haber tenido el hijo, son igualmente atendidas en este período postparto.

Las jóvenes que llegan al SOMS proceden generalmente de pueblos pequeños $o$ de otras provincias, pues cuando una mujer soltera queda embarazada por lo general no tiene el hijo en su pueblo o ciudad y mucho 
menos si quiere renunciar a él. En las grandes ciudades todos los marginados pasan más desapercibidos. Llegan enviadas por IRES, Cáritas o asistentas sociales. Por lo general son muy jóvenes y su situación se atribuye al mal ambiente familiar y al bajo nivel cultural, unido a la falta de responsabilidad. La mayoría tienen trabajo y no del mejor.

Aunque muchas de las madres solteras que van a este lugar se muestran alegres y trabajan mucho para sacar a su hijo adelante, su estado es de angustia casi permanente, sobre todo al principio, por el temor, soledad y rechazo que sufren y por la serie de dificultades que tienen que vencer.

Ésta es una de las razones por las que esta organización no es partidaria de los Centros residenciales especiales para madres solteras, que no hacen más que subrayar la marginación y aumentar la angustia y la sensación de culpabilidad e impotencia, puesto que el ambiente que se crea gira forzosamente en torno al mismo tema.

La organización está muy pendiente de todas las mujeres que la visitan, acompañándolas durante el parto, visitándolas, escuchándolas, animándolas, aconsejándolas, tratando de comprenderlas sin juzgarlas en ningún momento.

En lo referente a información sobre anticonceptivos, los Centros en general no son demasiado explícitos. En la Maternidad se pregunta a las que ingresan si quieren recibir información sobre anticonceptivos, en cuyo caso se les informa sobre pastillas. En Villa Teresita no se les habla de métodos anticonceptivos, pues aseguran que ya los conocen. Tampoco se da ninguna información en la Residencia Santa Eulalia, donde se aceptan los anticonceptivos como un mal menor. Si las interesadas piden información se las envía al médico, si no, no se les dice nada. En el Hogar Santa Isabel son informadas de la anticoncepción por el sacerdote-médico, siempre dentro de los márgenes de la moral vaticana y de cara a un futuro matrimonio, pues, evidentemente, toda relación sexual extramatrimonial está moralmente excluida. En Orientación de la Joven creen que los anticonceptivos son suficientemente conocidos, aunque no se descarta una orientación personal por parte de la asistenta social El SOMS está a favor de los anticonceptivos, cuyo uso aconseja y difunde, pues muchas los desconocen.

Ninguno de estos Centros acepta el aborto.

A la vista de lo expuesto, hay que preguntarse de nuevo por qué subsisten aún estos Centros. Su existencia intitucionalizada tiene un fundamento, aunque no una justificación actual, en la citada moral discriminatoria y en la falta de una legislación adecuada. Esta ausencia legal origina, como un fenómeno repetido a través de la historia, la aparición de personas o grupos de personas con unas características definidas que, al no 
tener la debida asistencia o protección social, recurren a benefactores, centros de caridad o cualquier otro tipo de fundaciones-parche, que surgen como solución momentánea a la sombra de una injusticia social y que, en cierto modo, la perpetúan, a pesar de su buena voluntad inicial. Pues no todas las instituciones son conscientes de su interinidad ni tan siquiera de su desfase actual.

Así, en cuanto a las residencias visitadas, es evidente que no todas ellas pueden englobarse en el mismo grupo, pues si la labor de algunas es, en mi opinión, francamente nefasta, otras guardan un mínimo respeto por la persona y su situación. Existe, no obstante, una característica común a todas ellas, que es la de la marginación social, la cual es de por sí negativa.

Las residencias, en líneas generales, predisponen a la cerrazón, disminuyen la posibilidad de trato con el exterior y dado el ambiente interno de gestación ilegal, se favorece un estado colectivo de depresión, angustia, impotencia y culpabilidad, en mayor o menor grado.

El hecho de que esta ambientación afecte más a unas residentes que a otras, es debido a su estado de ánimo al ingresar en el centro y, sobre todo, a la actitud que allí encuentran. Este aspecto tan importante del trato a la embarazada como persona en una situación equis y de la actitud hacia ella, no depende tanto del. contexto social y de los esquemas legales como de las personas responsables de las residencias, de su ideología y de su valoración de la persona.

En este sentido podríamos trazar una espiral de actitudes que van desde posiciones claramente negativas o pasivas a otras de total apoyo y colaboración activa.

El aspecto religioso y moralizante, que tanto peso ha tenido en nuestra cultura, se inmiscuye aquí también a través de las personas religiosas más tradicionales, con un claro matiz de culpabilización y arrepentimiento y de manera más suave por parte de las religiosas menos conservadoras, pero, aun así, con más aire de resignación que de defensa o acción.

Puede observarse la misma postura en cuanto a los métodos anticonceptivos, a cuya difusión, paradójicamente, se le presta menos interés cuanto mayor censura moral se aplique a la situación de las residentes por parte de los respectivos centros.

Creemos, pues, que el balance no resulta nada favorable a los centros residenciales, a cuya desaparición deberían contribuir tanto la legislación como la opinión social que ahora los consiente y los mantiene ocupados. 


\section{Situación posterior}

Enfrentarse a la sociedad con un hijo sin padre oficial es para cualquier mujer una situación difícil, cuanto más si ha seguido el largo proceso ya descrito de abandono afectivo y económico por parte de familia y amigos y de estancia en una residencia más o menos traumatizante. Su futuro y el de su hijo no resultan nada prometedores.

Pero la sociedad, generosa siempre con sus marginados, ofrece una salida, no exenta de crueldad, a las madres solteras que no quieren cargar toda la vida con este apelativo y con los disgustos y dificultades que comporta. El sistema emocional de estas mujeres, tan vapuleado ya, se enfrenta a una nueva y dolorosa prueba: la adopción.

Yo me quedé con mi hijo y opino que si una madre puede cuidar a su niño, es mejor que lo tenga con ella, pero considero que si una mujer, por las causas que sean, todas las cuales son dignas de respetar, no puede o no quiere tener a su hijo con ella, es mejor que lo deje con quien pueda cuidarlo y educarlo. Eso sí, todo antes de mandarlo a un orfelinato.

Nos remitimos nuevamente a los centros asistenciales, pues son los que se encargan habitualmente de tramitar las adopciones.

En la Maternidad, la institución es totalmente partidaria de la adopción y rechaza toda acusación de beneficio económico. Los padres adoptivos pagan 100.000 pesetas que pasan a manos del abogado, pues la Maternidad está totalmente financiada por la Diputación. La teoría es la de que una mujer soltera es incapaz de sacar un hijo adelante por sí sola y de que la única solución es dejar al niño en manos de otras personas. «Generalmente están desorientadas sobre qué hacer, si quedarse con el niño o dejarlo. Como no ven realmente su situación, nosotros les ayudamos. Les preguntamos si quieren que les aclaremos la situación, les decimos que están liadas, pues en realidad no desean al hijo, pues les recuerda al padre y en el momento en que nazca verán que se parece a él y no le querrán, sino que lo considerarán como una carga, como un obstáculo para todos sus planes, que no podrán llegar a quererio, pues no ha sido fruto de algo deseado. Hay otro hecho que nunca se tiene en cuenta. Lo descubrí cuando hace unos años estuve haciendo un estudio sobre los niños adoptados y vi que el niño adoptado vive muy bien, muy feliz, con mucha afectividad, pues los padres adoptivos son dos veces padres, una por el hijo que quieren tener y otra por la forma de tenerlo, que les lleva a darle mucho. Hay madres solteras que son indecisas, que no saben qué hacer. Entonces espe- 
ramos, pero a los seis meses el niño pasa a adopción, no teniendo derecho sobre él. Tuvimos un caso de una chica de trece años que era muy despierta e inteligente, pues en seguida comprendió que no podría tener al niño, que habría que darlo a ot:os padres, los cuales estarían en condiciones de ofrecerle una afectividad, una serie de comodidades...»

En el Hogar Santa Isabel, la superiora responde cautamente que no hay una norma general. No obstante y dentro del ambiente de culpa e impotencia que respira la futura madre, se favorece y alimenta por todos los medios la idea de que no va a poder salir adelante con su hijo. No se considera que una mujer sola pueda asumir todas las funciones familiares y por eso, sobre todo si es muy joven y la familia no acepta al niño, lo más aconsejable es la adopción, para la que se le facilitan todos los trámites, cargando a la cuenta de los padres adoptivos los gastos de parto, estancia, etcétera, etcétera, etcétera, en la cantidad que las monjas consideran oportuna y que ellos pagan sin rechistar.

Tanto en la Residencia Santa Eulalia como en Villa Teresita, parecen no tener ningún interés personal. en la adopción y consideran que concierne total y exclusivamente a la madre la decisión de quedarse con su hijo o no. Si lo tienen sin haberlo querido (violación, etcétera), generalmente piden que lo adopten, pues no lo sienten como suyo. Aunque hayan decidido quedarse con él, todas sienten en principio un rechazo hacia él, en cuanto que representa un obstáculo muy grande en su vida.

Todos los centros asistenciales coinciden, en líneas generales, en que es mejor la adopción, aunque no por las mismas causas. En la Maternidad y en el Hogar Santa Isabel parten de una ineptitud por parte de la madre y de su incapacidad para afrontar la situación. En la Residencia Santa Eulalia la idea es similar, pero más matizada, considerando que para el niño es más conveniente la adopción, pues una mujer sola «no puede darle ambiente familiar». «Además -dicen-, durante los dos primeros años los niños necesitan a la madre exclusivamente y a partir de esa edad precisan de la autoridad de un hombre.»

Una visión más amplia corresponde a Villa Teresita, donde consideran más favorable la adopción tanto para la madre como para el niño, debido a las dificultades económicas y sociales con las que la madre habrá de encontrarse indefectiblemente y que repercutirán en el niño.

La adopción se realiza en el momento del parto y todas las opiniones coinciden unánimemente en que lo más beneficioso para ambos es que la madre no vuelva a ver a su hijo, pues el niño viviría entre dos familias y la madre estaría en constante tensión emocional.

Evidentemente, creemos que todas estas opiniones parten de la experiencia repetida en estos centros, de madres solteras solas, abandonadas de 
todo su anterior círculo social, amontonándoseles los problemas de vivienda, trabajo, cuidado del niño, etcétera.

Tenía que pagar a una señora mayor para que lo cuidara, bueno, lo malcuidara. Cuando se hizo un poco mayor, dos años, lo llevé a una guardería, pero era demasiado cara y lo tuve que sacar. Fue de mano en mano. Luego cambié de vivienda y lo cuidaba la dueña de la casa donde vivía. Me sacaba bien el dinero, pero no tenía más remedio si quería seguir trabajando y dormir bajo techo.

A nuestro modo de ver, la cuestión está mal enfocada al hablat de ineptitud o decir que una mujer sola no puede dar a un niño ambiente familiar ni autoridad. En primer lugar, esto es discutible, y en segundo lugar el problema está en los que la dejan sola y en por qué lo hacen. El niño, todo niño, tenga padres o bisabuelos, necesita un «ambiente». Un ambiente en el que haya personas mayores, personas jóvenes, niños, todos ellos sustitutivos de las grandes familias de pueblo en las que todos los mayores eran un poco abuelos, un poco padres o un poco tíos de cada niño. Un ambiente grato, estable y cariñoso, donde el niño se vea rodeado de afecto y pueda adquirir nociones válidas de comportamiento y comprensión de la vida y de las cosas.

No es nuestra intención meternos a juzgar ahora si la actual pareja ciudadana es capaz de cumplir estos requisitos adecuadamente, pero lo que sí es verdad es que para una mujer sola es mucho más costoso, pues ha de rehacer su «ambiente» mientras cuida del niño y procura casa y comida para ambos.

Dentro de esta línea, el SOMS es partidario - y lo apoya- de que la madre se quede con su hijo. Están convencidos de que una mujer sola puede cubrir perfectamente los papeles familiares (afecto, autoridad manutención, etcétera). El problema, como veremos, está en las dificultades que a causa de la moralidad social se le crean.

Quedarse con el hijo plantea a la madre de inmediato el problema económico. La mayoría dejan el trabajo y cambian de ambiente, por temor a que las echen, por vergüenza y miedo a ser rechazadas por los compañeros, o porque el padre de su hijo trabaja en el mismo sitio. Es decir, ellas se quedan con el hijo y ellos con el trabajo, y si además él es casado, se consideran culpables, porque no pueden «regularizar» su situación.

Creo que el factor económico es el que más determina la situación de una madre soltera, sin olvidar el nivel de equilibrio 
que tenga, aunque este equilibrio puede empeorar o agravarse, según se presenten las circunstancias.

A la hora de encontrar trabajo se les amontonan las dificultades debido a su práctica o no en trabajos anteriores, malos horarios de las guarderías que no compaginan con los horarios de trabajo, precios elevados de las mismas, etcétera. Las de nivel económico más alto se encuentran con más problemas, pues no están acostumbradas a trabajar $\mathrm{y}$, aunque tengan más estudios, tampoco encuentran fácilmente un trabajo adecuado a los mismos y les cuesta amoldarse a lo que salga.

Carta social europea, Turín, 10-X-61:

Parte I, art. 17:

La madre y el niño, independientemente de la situación matrimonial y de las relaciones de familia, tienen derecho a una protección social y económica adecuada.

Parte II, art. 8:

-Descanso de 12 semanas como mínimo antes o después del parto, ya sea por vacaciones pagadas, por prestaciones de la Seguridad Social o por fondos públicos.

-Es ilegal el despido por maternidad.

- Asegurar a las madres que cuidan y crían a sus hijos las pausas suficientes para hacerlo...

En Orientación de la Joven consideran muy importante que la gestante, mientras busca un nuevo alojamiento y se enfrenta a su nueva situación, no abandone su trabajo, si es que lo tiene. En cualquier caso, se le ayuda a buscarlo, mayormente en el servicio doméstico. Comentando el hecho de que la mayoría de las madres solteras tenga que optar por esta profesión, sea cual fuere su trabajo anterior o sus estudios, nuestra entrevistada responde que sí es lamentable, pero que el problema del subempleo afecta a muchos profesionales, pues es propio de la crisis económica actual, y que en principio lo importante es tener un trabajo con un horario estable y seguridad social para la madre y el niño.

En su opinión, el mayor problema para la madre soltera es el de la vivienda, pues no puede pagar ella sola el alquiler de un piso y se le plantean dificultades de convivencia si lo alquila con más personas debido a las enfermedades del niño, llantos nocturnos, etcétera. Las que tenían un empleo que les permitía trabajar durante el embarazo (Telefónica, enfermeras, etcétera) que les da una cierta seguridad económica, se van a vivir a un piso con su hijo y, a veces, con una compañera. 
Los centros asistenciales consideran como mejor solución reintegrarse a la familia si ésta las acepta o agruparse en residencias para madres sol. teras que trabajen.

Al parecer, queda aún otra solución, pues según afirma la superiora del Hogar Santa Isabel, "ya se suelen casar», con lo cual, por lo visto, se solucionan todos los problemas. También en Santa Eulalia ven como mejor solución la reinserción en la familia o el matrimonio, pero para esto último la interesada habría de ser muy «formal» y por supuesto sabedora de que a medida que se fuera haciendo mayor disminuiría la posibilidad de dar viabilidad a esta solución.

No todas opinan igual:

No pienso volver a liarme con ningún hombre más, no quiero volver a tener problemas, no soporto la idea. Me he resignado a vivir sola con el niño y no creo que haya posibilidad de salir de esta situación.

No estoy de acuerdo con la familia tradicional, no creo en su valor tal como funciona actualmente, pues el padre tiene una función de dominio. No me preocupa que mi hija no tenga un padre reconocido por la ley. Lo importante es el trato que el padre tenga con los hijos. Por este motivo, busqué una guardería en la que también hubiera educadores masculinos, para que la niña no estuviese solamente con mujeres, pues pienso que debe de entenderse tanto con hombres como con mujeres. Creo conveniente que la niña sepa que su padre existe, pero que no convive conmigo, que no estamos casados. La niña no encuentra a faltar la figura del padre natural. Trata mucho con su abuelo y con los cuidadores de la guardería. La realidad es que los otros niños de la guardería no ven mucho a sus padres...

A la vista de la apremiante necesidad existente en cuanto a cuidado del niño, el SOMS montó una guardería para madres solteras en la calle Cucurulla, en Barcelona. La guardería CUC, creada gracias a un donativo particular de tres millones de pesetas, va subsistiendo gracias a las aportaciones de Cáritas, de algunos socios y de las cuotas mensuales.

Aquí son atendidos 25 niños de un mes a dos años de edad, que pueden permanecer las 24 horas del día bajo los cuidados de dos puericultoras que se turnan cada ocho horas. Hay, además, dos ayudantas que refuerzan las horas punta y una asistenta social. Una cocinera y una señora de la limpieza. Aunque lamentan la falta de espacio y la insuficiencia de plazas (todos los días tienen peticiones de ingreso), los niños están muy 
bien atendidos y sus madres pagan 5.600 pesetas mensuales (de las 14.000 que cuesta) por tenerlos aquí. Casas comerciales y personas particulares proporcionan ropa y comida.

Respecto a la madre, aunque cada caso es distinto y no se puede generalizar, hay una serie de características más o menos comunes. Así, en su mayoría son venidas de otras provincias, con nivel económico y cultural bastante bajo, jóvenes (19-25 años), viven en pensiones y todas ellas trabajan, la mayoría de camareras nocturnas o de asistentas domésticas.

Sus conocimientos sobre anticoncepción suelen ser nulos, pero no así después de haber tenido el primer hijo. Se sienten bastante angustiadas por su situación y por la fuerte marginación social de que son objeto. A más de una la han echado de la casa donde servía por decir que tenía un hijo. Están necesitadas de afecto y de personas que las escuchen y las comprendan.

La reacción de las familias es de todo tipo, pero nunca consoladora: unas no quieren saber nada del niño ni de la madre, otras admiten a la madre sin el niño, otras consienten en ver al niño de vez en cuando.

Aunque en principio muchas madres sienten rechazo o despreocupación hacia el niño, acaban interesándose por él, sobre todo cuando ven que no las reconoce o que las rehúye. Los niños, cuando se sienten abandonados por su madre, transfieren su afectividad a una de las puericultoras. $\mathrm{La}$ guardería vigila mucho este aspecto y nunca se han encontrado con casos verdaderamente problemáticos (la concienciación y el interés de la madre suelen ir en aumento).

La guardería es consciente de ser un parche, pero opina que es mucho peor que los niños estén en manos de cuidadoras que cobran de 8.000 a 10.000 pesetas por tener al niño unas horas y mal atendido. No obstante, considera que son ya niños marcados y que actualmente no hay una solución viable para su situación y la de sus madres.

Porque el proceso discriminatorio sigue su camino. Si se soluciona el problema de la guardería, el siguiente es el de la escolarización del niño, pues hay todavía colegios que ponen objeciones al ingreso de niños sin padre oficial.

\section{Aspectos jurídicos}

Creemos conveniente abrir un pequeño paréntesis para citar las normas legislativas que inciden directamente en el problema que tratamos y que nos demuestran que en España no hay leyes que permitan a una mujer soltera asumir la maternidad de un modo responsable y con garantías de que se la respetará como mujer y como madre. 


\section{a) Registro Civil:}

Si el padre no reconoce al hijo, a la madre soltera se le niega el libro de familia, con lo que se instituye una discriminación perenne a nivel ofcial, de modo que ante cualquier trámite legal tiene que dar razón de por qué no hay representante legítimo de la patria potestad, que ella ejerce de modo siempre provisional y como emergencia, en defecto del padre. Éste puede reclamar en cualquier momento la patria potestad, si le interesa.

La Ley de Registro Civil de junio de 1957, afirma:

Art. 55: Los hijos naturales reconocidos sólo por la madre llevarán los dos primeros apellidos de ésta, pudiendo invertir el orden.

Art. 59: El Juez de Primera Instancia puede autorizar:

El cambio del apellido «Expósito» u otro similar por uno de los pertenecientes al peticionario, o por un apellido corriente. Sólo se requiere para ello que exista causa justificada y que nadie resulte perjudicado.

Art. 198: La inversión de apellidos podrá formalizarse a petición del hijo o de su representante legal, mediante declaración en el registro de domicilio.

\section{b) La patria potestad:}

Si el hijo ha sido concebido de una persona casada, el problema que se plantea al respecto no ofrece muchas alternativas; por no estar reconocida legalmente la investigación sobre la paternidad (en España) el hijo queda normalmente bajo la tutela de la madre, salvo en el caso de que el padre le aceptara entre su familia legítima, previo consentimiento de la esposa.

Si el hijo ha sido concebido de un hombre soltero, puede éste reconocer al niño y legalizar así su situación, quedando él como titular de la patria potestad con los correspondientes derechos y deberes. Lo que ocurre es que estos deberes son fácilmente soslayables, dado que se puede alegar insuficiencia de recursos y dejar a la madre con el problema de facilitar al niño alimento $\mathrm{y}$ vestido. Los derechos que otorga la patria potestad implican que el niño necesitará del permiso paterno para realizar cualquier acto oficial y que la madre tiene siempre ante sus ojos la amenaza de que le arrebaten a su hijo.

$\mathrm{El}$ art. 134 del Código Civil expone así los derechos del niño (deberes del padre): «El hijo natural reconocido tiene derecho:

-A llevar el apellido del que lo reconoce.

-A recibir alimentos del mismo.

-A recibir del mismo, en su caso, la porción hereditaria que se determina en este Código.»

En caso de que la madre soltera quiera solicitar que el padre natural 
que ha reconocido al hijo sea privado de la patria potestad en beneficio de la madre, debe acudir a los tribunales y sólo lo conseguirá si puede acreditar que el padre ha incurrido en alguna de las causas que impone el Código Civil:

-Dar malos tratos al hijo o darle consejos o ejemplos corruptores.

- Sentencia en causa criminal o en pleito de divorcio.

- Incapacidad o ausencia del titular, declarada judicialmente.

Art. 487 del Código Civil: «Será castigado con las penas de arresto mayor y multas de 10.000 a 50.000 pesetas el que dejare de cumplir, pudiendo hacerlo, los deberes legales de asistencia inherentes a la patria potestad...»

Lo difícil es calibrar si «puede hacerlo», dado que hay un margen de excusas (carencia de medios...) difícilmente constatables que hacen que normalmente el padre mantenga la patria potestad a pesar de no cumplir con los deberes que ella implica, y que la madre carezca de recursos para conseguir su cesión.

En general, el que la madre ceda al reconocimiento del hijo por parte del padre soltero, presenta más problemas que beneficios, ya que - caso de haberlos- éstos son únicamente de índole económica, y el padre que está decidido a ayudar a su hijo lo hará igualmente aunque no lo haya reconocido legalmente.

Hace un año el padre me planteó dar su apellido al niño, a lo que yo me negué, por temor a que se lo lleve tal como podría hacer amparado por las leyes por el derecho que el padre tiene a la patria potestad sobre los hijos. Prefiero que cuando el niño tenga doce años pueda ir: con el que quiera. La actitud de la gente que conozco es la de que tendría que legalizar la situación.

Al parecer, en los últimos decretos legislativos se suprimen del léxico legal los vocablos «natural» e «ilegítimo» aplicados, como se ha visto, a los hijos de madre soltera, lo cual no altera los puntos básicos de la discriminación legal. Creemos que los párrafos anteriormente citados merecen una reforma mucho más seria y profunda.

\section{Agrupación de madres solteras}

En los últimos años ha habido intentos de formar entidades que se ocupasen de la problemática social de la madre soltera, todos los cuales han fracasado por no ser las propias interesadas las que lo protagonizaban, 
sino abogados $\mathrm{u}$ otras mujeres preocupadas por tal cuestión, pero sin sentirse afectadas.

Actualmente existen tres agrupaciones de reciente creación, lo que supone una situación de planteamientos a varios niveles, a perfilar. Funcionan en Castellón, Barcelona y Madrid. Insertamos información de la de Barcelona, por razones de proximidad y de relación con las entrevistas realizadas.

La Agrupación de Madres Solteras existente en esta ciudad fue promovida por un grupo de las mismas, a finales de marzo de 1977. Se dieron a conocer por la radio, incrementando así el número de personas interesadas en trabajar en este problema.

Integradas en la Coordinadora Feminista, tratan primeramente de conseguir la formación de promotoras a nivel provincial, para después constituirse en Asociación. El motivo fundamental que les mueve a formar esta Agrupación es la necesidad de que la madre soltera salga de casa, no se encierre en sí misma, reivindique sus derechos y luche por una igualdad respecto a la madre casada.

Consideran que la madre soltera es una persona que convive con su hijo y haciendo frente a la sociedad ha de salir adelante sin la ayuda de nadie. Su principal condicionante es el factor económico.

En el momento presente, esta Agrupación reivindica una serie de puntos que irá renovando, a medida que el grupo se amplíe, a través del mayor número de aportaciones personales y planteamientos:

- Patria potestad compartida.

- Abolición del libro de afiliación. trimonio.

-Igualdad de derechos entre hijos habidos dentro y fuera del ma-

- Investigación de la paternidad, a nivel estatal.

-Educación sexual desde la primera infancia.

-Anticonceptivos a cargo de la Seguridad Social.

-Investigación de las condiciones sanitarias y jurídicas, así como de la marginación social existente en instituciones públicas y privadas.

-Derecho al trabajo, teniendo en cuenta su situación.

Existen otros aspectos muy importantes que se plantean, frente a los cuales han decidido no definirse hasta ver incrementado el grupo.

-Aborto: plantea dificultades en el seno de la agrupación, debido a las diferentes posiciones que existen que van de un extremo al otro. Si están de acuerdo en que el motivo básico que hace necesario el aborto es 
la falta de educación sexual, cuestión que creen ha de abordarse antes que la del aborto.

-Adopción: aunque lo están investigando, creen que es un negocio y lo condenan como tal.

-Centros asistenciales: respecto a las instituciones dedicadas a atender a la madre soltera, creen que han de abolirse como tales, pues marginan a la madre y al hijo. La mentalidad de quienes rigen estas instituciones (en general monjas) no puede asumir el problema, pues lo ven bajo el punto de vista moral de culpabilidad e «hijos del pecado». Por otra parte, las mujeres que acceden a estas instituciones tienen una postura individual «acosadas» por su problema, sin ver en aquel momento una posible solución, llevando consigo un gran conflicto a nivel familiar y social, en la mayor parte de los casos.

La agrupación, en este sentido, se pronuncia en contra de las decisiones individuales, pues considera que se trata de una dificultad general.

$\mathrm{La}$ alternativa que plantea, en principio, es:

Crear pisos para madres solteras que les permita tener libertad total de decisión y de acción y, de esta manera, se dejaría de fomentar la decisión individual, o sea, el sentimiento de culpabilidad frente a la sociedad y al propio hijo.

Para el futuro se pretende que no sean necesarios los pisos, pues la madre soltera debe ser aceptada como mujer que tiene un hijo $\mathrm{y}$, consecuentemente, han de abolirse las diferencias existentes entre quienes son madres dentro y fuera del matrimonio.

\section{Conclusiones}

Después de lo expuesto, creemos poder constatar el papel primordial de la mentalidad moralista, en el rechazo social que sufre la madre soltera.

Esto puede apreciarse primeramente en la actitud de la familia que no se desentiende de su hijo por motivos económicos, ideológicos o de otra índole, sino por cuestión puramente moral.

Es la misma mentalidad que se observa en los centros asistenciales, lugares de trabajo, amigos..., en la sociedad en general y, lamentablemente, en la propia interesada.

Repentinamente, una mujer se ve enfrentada a la sociedad, en todas las facetas de su vida, por no llevar a su lado un hombre, protector de su honor y de su hijo.

El castigo es ejemplar. Sin familia, trabajo ni amigos, recurre a un 
centro asistencial donde la actitud moralizante se agrava, acrecentando los sentimientos de culpa, angustia y desequilibrio psíquicos, basados en la conciencia de la soledad a la que se ve sometida. Hay, además, todo un intento «desinteresado y altruista» para convencer a la madre de su impotencia para educar y mantener a su hijo y de lo beneficioso para ambos de su renuncia a él y su posterior adopción. Una vida de lucha y malos tragos si decide quedarse con su hijo.

Paradójicamente, la moral, la ley y el orden protegen al hombre. En primer lugar, abandona a la mujer por haberla dejado embarazada, probablemente con mayor conocimiento de causa por parte de él que de ella.

Puede reconocer a su hijo o no, según lo desee. Aunque no lo vea nunca, puede decidir sobre cualquier aspecto legal que se relacione con el hijo. intactos.

Su dignidad personal, su prestigio social, su puesto de trabajo, quedan

Parece incomprensible que pueda seguir manteniéndose una discriminación y una injusticia tan descaradas y, lo que es más triste, con el beneplácito general de la sociedad.

Urge un replanteamiento legal, social y mental.

Es exigible al Estado la reforma del Código Civil y de las leyes discriminatorias de la mujer, como mujer y como madre.

La reforma social ha de empezar desde la educación infantil con información sexual a todos los niveles. Con distribución libre y gratuita de métodos anticonceptivos. Con la legalización del aborto.

La mentalización será lo más difícil. Según la cerrazón de cada uno. Hay que airear la cabeza y revisar conceptos y opiniones. Un marginado no es un bicho raro. Se «hace raro» cuando lo marginan. Una madre no es rara. Pero no todas las mujeres han sido madres cuando han querido. $\mathrm{Y}$ ahí está la queja. Cuando una lo desee. Independientemente de que quiera a un hombre o no, de que quiera hacer el amor con él o con otro. Sin sustos. Sin angustias. Sin salir del propio contexto familiar, laboral, social. Con posibilidades de seguir desarrollando al máximo la capacidad personal y la actividad social.

Disfrutando con el hijo y con la vida. 